\title{
Assessment of problematic severe asthma in children
}

K.C. Lødrup Carlsen, G. Hedlin, A. Bush, G. Wennergren, F.M. de Benedictis, J.C. De Jongste, E. Baraldi, C. Pedroletti, A. Barbato, K. Malmström, P. Pohunek, S. Pedersen, G.L. Piacentini, R.J.M. Middelveld and K.H. Carlsen on behalf of the PSACI (Problematic Severe Asthma in Childhood Initiative) group

\begin{abstract}
Assessment of problematic severe asthma in children should be performed in a stepwise manner to ensure an optimal approach. A four-step assessment scheme is proposed. First, a full diagnostic work-up is performed to exclude other diseases which mimic asthma. Secondly, a multi-disciplinary assessment is performed to identify issues that may need attention, including comorbidities. Thirdly, the pattern of inflammation is assessed, and finally steroid responsiveness is documented.
\end{abstract}

Based upon these four steps an optimal individualised treatment plan is developed. In this article the many gaps in our current knowledge in all these steps are highlighted, and recommendations for current clinical practice and future research are made.

The lack of good data and the heterogeneity of problematic severe asthma still limit our ability to optimise the management on an individual basis in this small, but challenging group of patients.

KEYWORDS: Asthma, child, diagnostics, severe

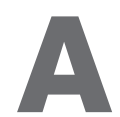

lthough the majority of children with asthma respond well to standard therapy, a significant proportion [1] still have problematic, severe disease that is not controlled with conventional management. A birth cohort identified $4.5 \%$ of the asthmatic children with "severe asthma", whereas others found that $39-55 \%$ of children with problematic severe asthma had "difficult to treat" asthma [2,3]. A recent paper [4], which discussed definitions, classifications and age-related presentation of problematic severe asthma in childhood, suggested asthmatic children warranted further investigation and outlined triggers of asthma exacerbations. It was emphasised that many children may have factors apart from the underlying severity of asthma that contribute to their severe disease, including comorbidities, socioeconomic problems, adverse environmental exposures (such as tobacco smoke, relevant allergens and other harmful factors), psychological problems and especially poor adherence to treatment.

Age is relevant not only for the presentation of disease and the underlying pathophysiology, but also for the way the child can be assessed. Our article focuses on age-appropriate assessment methods for which there is a scientific basis, and reports on a step-wise approach to assess diagnostic possibilities, airway inflammation and therapeutic responses to corticosteroids (fig. 1). Essentially, these steps lead to the child being placed in one of four categories: wrong diagnosis ("not asthma"); asthma with significant comorbidities that need to be addressed ("asthma plus"); asthma which is not responding to treatment because the basics have not been got right ("difficult asthma"); and true asthma ("severe, therapy-resistant asthma"). It is patients

Previous articles in this Series: No. 1: Hedlin G, Bush A, Lødrup Carlsen K, et al. Problematic severe asthma in children, not one problem but many: a GA²LEN initiative. Eur Respir J 2010; 36: 196-201. No. 2: Xepapadaki P. Papadopoulos NG. Childhood asthma and infection: virus-induced exacerbations as determinants and modifiers. Eur Respir J 2010; 36: 438-445. No. 3: de Groot EP, Duiverman EJ, Brand PLP. Comorbidities of asthma during childhood: possibly important, yet poorly studied. Eur Respir J 2010; 36: 671-678. No. 4: Kabesch M, Michel S, Tost J. Epigenetic mechanisms and the relationship to childhood asthma. Eur Respir J 2010; 36: 950-961.

AFFILIATIONS

For a fill list of authors affiliations see the Acknowledgements Section. The PSACI group members are also listed in the Acknowledgements section..

\section{CORRESPONDENCE}

K.C. Lødrup Carlsen

Dept of Paediatrics, Women and

Children's Division, Oslo University

Hospital and the Faculty of Medicine

University of Oslo

NO-0407 Oslo

Norway

E-mail: k.c.l.carlsen@medisin.uio.no

Received:

June 142010

Accepted after revision:

Sept 182010

First published online:

Oct 282010 
in this last group who would be candidates for the expensive, and potentially hazardous, cytokine-specific therapies. Treatment of this last group will be covered in another article in this series. Finally, knowledge gaps will be discussed.

\section{STEP 1: EXCLUDE WRONG DIAGNOSIS}

It is crucial to get the diagnosis right. The most important differential diagnoses and their relevance vary geographically (e.g. tuberculosis and cystic fibrosis) and particular diagnostic vigilance should be exercised if the child is non-atopic. Tests include, but are not limited to: sweat test and genotyping for cystic fibrosis; nasal nitric oxide and biopsy for primary ciliary dyskinesia; high-resolution computed tomography (HRCT) scan for interstitial lung disease, bronchiectasis and airway malformations; and other relevant tests for systemic disease. Furthermore, a history of severe, persistent, unusual or recurrent infections should prompt immunological investigations including serum immunoglobulin (Ig)G (including subclasses),

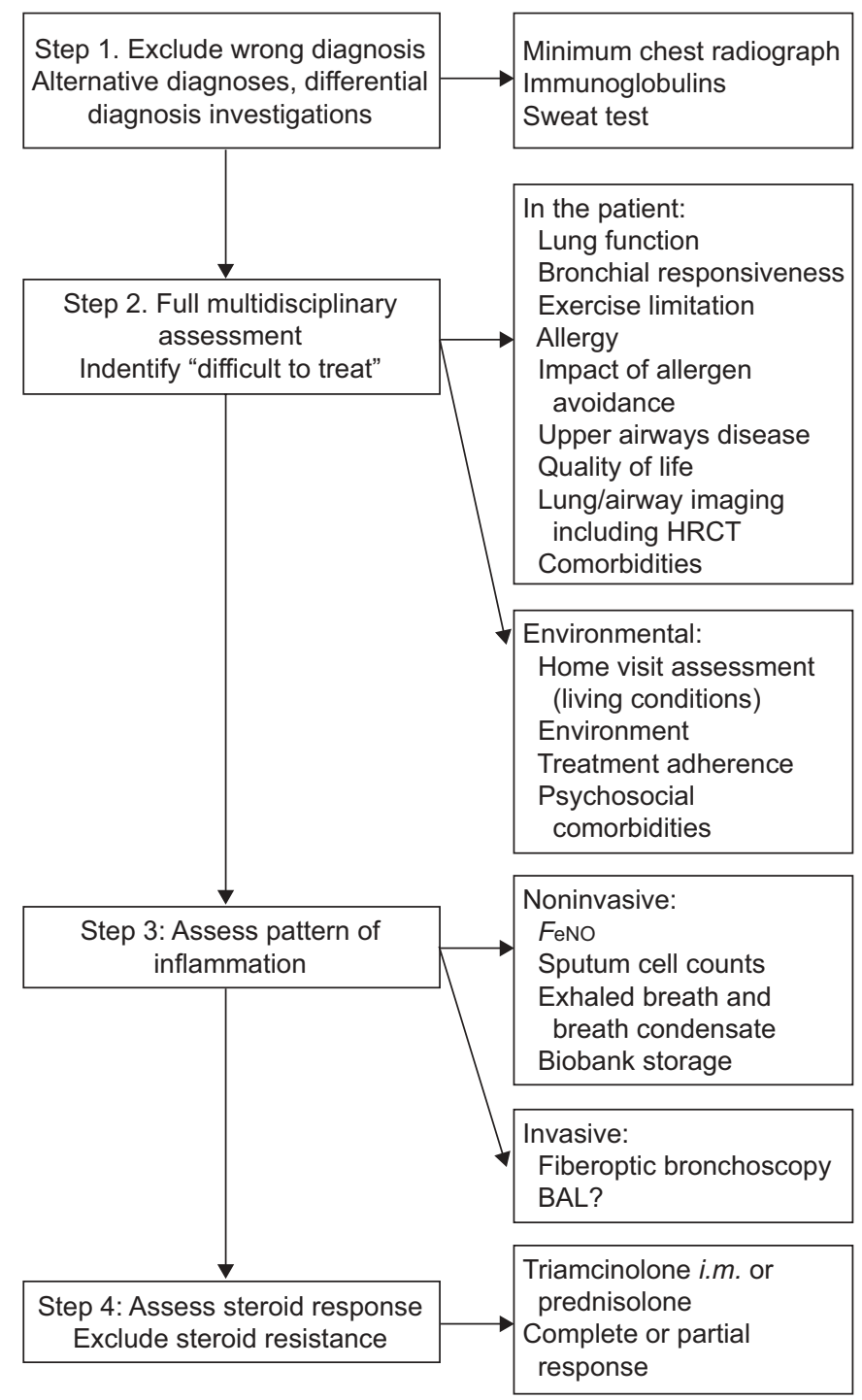

FIGURE 1. A step-wise assessment plan is recommended in problematic severe asthma. HRCT: high-resolution computed tomography; FeNO: exhaled nitric oxide fraction; BAL: bronchoalveolar lavage.
$\operatorname{IgM}$ and $\operatorname{Ig} \mathrm{A}$, evaluation of antibody response to common antigens and vaccines, and HIV testing. Studies of granulocyte and T-cell function may be warranted. Multisystem conditions, such as Churg-Strauss syndrome or Wegener's granulomatosis, should be considered. A focused approach guided by history and physical examination is more appropriate than slavishly performing every possible test on all children.

\section{Clinical recommendation}

A detailed re-assessment of the diagnosis should be performed in all patients whose asthma does not appear to be responding to treatment. Which test to perform should be based upon local disease prevalence, but in all patients the minimum tests to include are: a chest radiograph, $\mathrm{Ig}$ and a sweat test.

\section{STEP 2: FULL MULTIDISCIPLINARY ASSESSMENT In the patient}

Lung function

Spirometry and acute bronchodilator reversibility will usually have been part of Step 1, and failure to demonstrate variable airflow obstruction over time or with treatment should definitely lead to the consideration of alternative diagnoses. Although reduced lung function values are commonly included in asthma classifications in childhood, the scientific rationale for this is questionable. The requirement for a reduction in forced expiratory volume in $1 \mathrm{~s}$ (FEV1) as a diagnostic criterion for severe asthma in children $[5,6]$ or in management guidelines [7, 8] will exclude the majority of children who meet the other diagnostic criteria [9]. Children with problematic severe asthma have less impairment of lung function than adults [10-12]. Severe exacerbations appear to be associated with a more rapid decline in lung function in children but not adolescents [13]. This may be attenuated by treatment with inhaled corticosteroids [13]. Since children with severe asthma may have preserved FEV1, post-bronchodilator mid-expiratory flow rates, such as forced expiratory flow at $25-75 \%$ of forced vital capacity (FEF25-75), FEF50 [10, 14, 15] or the FEV1/forced vital capacity ratio $[12,14]$, may be more sensitive for (better reflecting bronchial obstruction) severe asthma than FEV1 $[12,14]$. However, many children with genuine severe, therapy-resistant asthma have normal spirometry when asymptomatic.

Nonetheless, spirometry is an important part of the assessment using relevant reference values $[16,17]$, since reduced FEV1 strongly supports problematic severe asthma [12]. One drive of the work-up is to identify children with persistent airflow limitation. However, for this condition there is no generally accepted definition in paediatrics and we suggest that children who, despite an adequate trial of systemic steroids (although we note that there is no uniformly agreed definition in paediatrics as to what is an adequate dose or duration) and acute response to bronchodilator, have an FEV1 of $>1.96$ Z-scores below the mean should be considered to have persistent airflow limitation.

Measures of airways resistance are not routinely performed and their added value to spirometry in assessment of disease severity is not demonstrated. Furthermore, measures are technically more challenging than spirometry and interpretation of measures are less standardised than is the case for spirometry. Thus, at present, such measures are more useful in research. 


\section{Clinical recommendation}

Spirometry and measurement of the immediate response to a bronchodilator should be performed (if age appropriate) in all children with problematic severe asthma.

\section{Research recommendation}

More longitudinal data should be collected on lung function growth in children with problematic severe asthma.

Assessment of trapped air and other more sophisticated tests of lung function need scientific evaluation in problematic severe asthma and may be useful for evaluation of therapy response and peripheral airflow obstruction.

\section{Bronchial hyperresponsiveness}

A bronchial challenge test may already have been performed as part of Step 1 and if a challenge test is negative in a child thought to be very symptomatic due to asthma, the diagnosis should be questioned. The association between increased bronchial hyperresponsiveness (BHR) and severe asthma $[14,18,19]$ was recently supported by a specificity of $90 \%$ of provocation dose of methacholine causing a $20 \%$ fall in FEV1 (PD20) methacholine of $<0.2 \mu \mathrm{mol}(<1 \mu \mathrm{mol}$ in [20]) to discriminate between children with severe versus mild-tomoderate asthma [12]. The increased BHR in children with more severe forms of asthma [19] is particularly important in relation to exercise-induced bronchoconstriction (EIB) [21] and to a lack of asthma control [22]. The indirect methods, including standardised exercise test [23], cold air inhalation with exercise [24], eucapnic voluntary hyperventilation [25] or inhaled mannitol [26], have different sensitivity and specificity for the diagnosis of asthma, as well as in response to therapy. The indirect tests, like exercise and mannitol inhalation are usually highly specific but with low sensitivity for asthma $[24,27]$, although their associations with problematic severe asthma in childhood is not known. Treatment guided by BHR measures was found to improve childhood asthma control in some [28, 29], but not all studies [30]. Although challenge tests in children with problematic severe asthma are not part of the routine evaluation in many places, they are important measures of asthma control [9, 31, 32] and should be performed in accordance with standardised protocols under close observation. In some patients, however, such tests cannot be performed due to bronchial obstruction or other contraindications.

\section{Clinical recommendation}

Assessing BHR (if baseline conditions allow) and exercise limitation should be part of routine assessment in problematic severe asthma whenever possible.

\section{Research recommendation}

Establishing the value of EIB testing and other direct and indirect measures of BHR in differentiating severe from less severe forms of asthma, as well as their role in monitoring problematic severe asthma, requires further studies.

\section{Allergy}

The risk of severe chronic asthma increases with multiple sensitisations and high total IgE levels [33, 34]. In fatal childhood asthma, allergens have been linked to the cause of death. This particularly relates to food allergens, such as peanut, but also to airborne allergen exposure such as animal dander, moulds [35] and high pollen levels in combination with physical exercise [36]. Hence, a thorough evaluation of possible allergies and their relevance to clinical disease and severity is mandatory in a child presenting with problematic severe asthma. The child's history is the most important part of that evaluation but needs to be complemented with further investigations [37]. Allergy testing should be considered in problematic severe asthma for the following indications: 1) to guide allergen avoidance measures; 2) if treatment with omalizumab is considered (this should be preceded by all reasonable attempts to exclude environmental allergens); 3) to identify the rare child with severe asthma and fungal sensitisation who may need avoidance measures and antifungal therapy; 4) if allergic bronchopulmonary aspergillosis (ABPA) is a possibility; and 5) to identify the rare non-atopic asthmatic, in whom the possibility of another diagnosis should be reconsidered.

The standard methods skin-prick testing and response radioallergosorbent tests (RAST) may give discordant results and should probably both be performed. Newly developed methods enable analysis of multiple antigen components that may prove helpful in differentiating between allergies that can cause life-threatening asthma and sensitisations of less importance for the disease severity [38].

Assessing the impact of allergen avoidance in any child with problematic severe asthma should be part of the clinical investigation. The value of house dust mite avoidance for asthmatic patients has been questioned [3, 39-42], but several lines of evidence suggest it may be useful in severe asthma. First, low-dose allergen exposure, insufficient to cause acute deterioration, may lead to steroid resistance by an interleukin (IL)-2 and IL-4 dependent mechanism [43, 44]. Secondly, the combination of viral infection, allergen sensitisation and high levels of exposure to that allergen in the home are predictive of severe exacerbations [45], and of these factors only allergen exposure is amenable to intervention. It is probable that the expense and inconvenience of allergen avoidance is more likely to be acceptable in children with severe asthma. In summary, we believe there is sufficient evidence to recommend avoidance of aeroallergens where possible in sensitised children with problematic severe asthma.

With regards to severe asthma with fungal sensitisation, a randomised controlled trial in adults and case reports in children suggest a treatment response to itraconazole therapy [46]. This treatment has the merit of being safe, although the interaction with budesonide may potentially lead to adrenal failure and must be considered.

As for ABPA, specific IgE to aspergillus may be a diagnostic clue which needs to be considered in children with problematic severe asthma and mould sensitisation [35].

\section{Clinical recommendation}

Skin prick testing and RAST tests should be part of the routine clinical work-up in problematic severe asthma, and relevant allergen avoidance should be instituted for sensitised children.

\section{Research recommendation}

Research is needed on: 1) how to respond to discordant results between RAST and skin prick tests; 2) whether analysis of 
multiple allergen components adds relevant information; 3) the clinical efficacy of allergen avoidance; and 4) the frequency and optimal management of severe asthma with fungal sensitisation.

\section{Upper airways disease}

Allergic rhinitis often co-exists with asthma [47] and upper airway disease may worsen asthma [48]. Treatment of allergic rhinitis has been advocated as an important component of asthma management $[49,50]$, but to what extent treatment of allergic rhinitis may improve asthma is controversial [51].

Studies on sinusitis treatment in problematic severe childhood asthma are lacking. However, upper airway evaluation, including anterior rhinoscopy when appropriate, should be part of the assessment of problematic severe asthma. Additional tests including sinus computed tomography (CT) or magnetic resonance imaging, which are more informative than plain sinus radiography studies in children, should be considered [52, 53]. Sinusitis has been reported in a high proportion of children with severe asthma [54] with or without nasal symptoms, and a relationship between abnormalities on sinus CT and bronchial eosinophilic inflammation has been shown in adults $[55,56]$. A trial of treatment for allergic rhinitis in children with problematic severe asthma would seem reasonable.

\section{Clinical recommendation}

Upper airway assessment is a routine part of the clinical assessment of problematic severe asthma. Allergic rhinitis should be treated, although the evidence that this will improve the asthma is limited.

\section{Research recommendation}

We need more work on comparisons of nasal and bronchial inflammation, and to what extent (if at all) upper airway samples reflect lower airway inflammatory phenotype.

\section{Quality of life}

Functional impairment in daily life is common in asthma [57]. Health-related quality of life (QoL) based on reports from the child and/or parents provide different information compared to traditional clinical measurements [58]. Overall, increasing asthma severity is associated with impaired health-related QoL [59], although the exact relationship has not always been clear [60]. We do not have sufficient information to recommend which QoL questionnaires should be used in problematic severe asthma, although it would seem sensible to recommend the use of asthma-specific QoL questionnaires, such as the Paediatric Asthma Quality of Life Questionnaire (PAQLQ) and the Paediatric Asthma Caregiver's Quality of Life Questionnaire (PACQLQ) [61]. Measures of QoL were recently found to improve phenotype discrimination in severe asthma [20], but the value of QoL measures in follow-up studies in severe asthma needs to be established.

\section{Clinical recommendation}

The PAQLQ and the PACQLQ should be available in the patients' native language and be completed as part of the assessment of problematic severe asthma. Optimal frequency of completing QoL questionnaires for monitoring purposes has not yet been established.

\section{Research recommendation}

More work is required on whether QoL questionnaires developed for mild and moderate asthma are appropriate for more severe disease.

\section{Imaging techniques}

Specific imaging issues in problematic severe asthma include the exclusion of other diagnoses (Step 1) and the use of imaging as a specific, clinically useful biomarker. Highresolution CT (HRCT) can be used in problematic severe asthma to study airway wall changes [62, 63]. Bronchial wall thickening on HRCT has been a consistent finding in children with problematic severe asthma and it may constitute an additional criterion of asthma severity [64]. The association between bronchial wall thickening seen on HRCT scans and thickness of the bronchial epithelial reticular basement membrane in bronchial biopsy seen in adult asthmatics has not been replicated in children [63]. At present there is insufficient evidence to recommend the routine clinical use of any imaging technique in problematic severe asthma.

\section{Clinical recommendation}

HRCT is not a routine investigation in the assessment of children with problematic severe asthma, and is only clinically indicated if there is diagnostic doubt.

\section{Research recommendation}

HRCT and other imaging modalities with safe image processing techniques specifically adapted for the use in children should be incorporated into research protocols, in order to try to determine any correlations with airway structure, treatment effects and prognosis.

\section{Comorbidities: asthma plus}

Other comorbidities have been discussed elsewhere [4], and are an integral part of the assessment. In particular, obesity can cause a non-inflammatory phenotype, and weight reduction should be encouraged. There should be a high index of suspicion for gastro-oesophageal reflux, particularly in young children.

\section{Environment}

Environmental assessments should include a home visit to ensure the indoor environment is optimal in relation to water damage, humidity and ventilation, mould exposure, general irritants, tobacco smoke and allergens.

Among children with difficult to treat asthma, ongoing environmental allergen exposure may occur in sensitised children despite advice to the contrary, and thus contribute to the severity of asthma [33]. Thus, a nurse-led visit to the child's home can be an important measure to evaluate the possible impact of allergy on lack of response to treatment [3]. Other facets of the home visit include assessments of adherence and psychosocial issues. The nurse should assess whether there is a complete set of in-date medication readily available within the home, whether the degree to which the child is supervised when taking medications is acceptable, and whether the ability to use the inhaler device is correct. The nurse should also obtain prescription records, as well as preferably use objective measures to assess adherence [65]. Merely collecting a prescription does not guarantee that the 
medication has been taken, but not collecting a prescription means non-adherence is a certainty. Finally, discussions of sensitive psychosocial issues are more likely to be informative if they take place in the home.

\section{Clinical recommendation}

Where possible, a home visit and detailed assessment of the environment, adherence, and psychosocial comorbidities should be performed.

\section{Research recommendation}

The longer term value of this intervention needs to be determined. We also need to know whether repeated visits and environmental sampling would be beneficial. We need to have better ways of assessing adherence in routine clinical practice.

\section{STEP 3: ASSESS PATTERN OF INFLAMMATION Airway inflammatory markers}

Although inflammatory markers in sputum, exhaled air, serum and urine can be measured, to date they have not been implemented as part of the clinical management for problematic severe asthma. The justification for their use is that many children are prescribed ever-higher doses of anti-inflammatory therapies, which does not seem logical if there is no residual inflammation. Furthermore, in the future, it is likely that patterns of inflammation may determine which treatment should be offered.

\section{Exhaled nitric oxide fraction}

Exhaled nitric oxide fraction $(F \mathrm{eNO})$ bears a loose relationship to eosinophilic airway inflammation. FeNO can predict eosinophil levels in bronchoalveolar lavage (BAL) [66], and can identify persistent eosinophilic inflammation in children with steroidresistant problematic asthma [67]. Since steroid treatment reduces FeNO, poor compliance should be suspected if $F$ eNO remains high despite the prescription of adequate doses of inhaled steroids. However, it would be a mistake to assume that asthmatic children who have a high FeNO are non-compliant, there are other causes, including excessive allergen exposure or steroid insensitivity. In adults, increased FeNO was recently shown to predict accelerated decline in lung function in problematic asthma [68]. It is not clear if the same applies to children. The measurement of $\mathrm{FeNO}$ at different flows may allow partitioning of NO production to proximal and distal airways.

Inevitably, all children will have been prescribed inhaled corticosteroids, and the relationship between FeNO and airway eosinophilia is closest in steroid naïve children. Thus, FeNO in severe problematic asthma is loosely indicative of the eosinophilic phenotype. The clinical role of FeNO in problematic severe asthma is still being determined.

\section{Sputum}

Sputum is usually obtained after induction with normal or hypertonic saline [69] after pre-treatment with a bronchodilator [70]. The reported success rate is up to $80 \%$ in dedicated research centres, increasing with patient age and probably with asthma severity [71-73]. The feasibility of repeated procedures is problematic in many children, which limits the clinical usefulness of sputum as a means to detect and monitor airway inflammation.
Four different inflammatory patterns have been reported: eosinophilic; neutrophilic; mixed eosinophilic and neutrophilic; and paucicellular [69]. However, surprisingly, sputum cytology appeared to be normal in the majority of school-age children with difficult asthma, with eosinophilia in as few as 30\% [71]. The clinical usefulness of soluble sputum markers in childhood problematic severe asthma has yet to be determined.

\section{Exhaled breath condensate}

Condensate from exhaled breath may reflect the composition of the airway lining fluid [74]. Exhaled breath condensate (EBC) collection is feasible in children, even during acute asthma. Few, if any, EBC biomarkers have been validated for clinical use, and considerable methodological challenges remain [74]. A recent study [75] demonstrated an increased level of EBC 8-isoprostane in children with problematic asthma suggesting a role for oxidative stress in this asthma phenotype.

The use of innovative "-omics" technologies, such as proteomics and metabolomics, may offer great potential in the future [76].

Other inflammatory markers in serum and urine of (eosinophilic) inflammation have, in the past, been used for asthma monitoring and management. These included eosinophilic products such as eosinophil cationic protein and eosinophilderived neurotoxin (eosinophil protein X), as well as cysteinylleukotriene metabolites. Unfortunately, none of these markers have been shown to be valuable in the diagnosis or monitoring of asthma, or in severity of the disease in the individual patient, even if associations have been found in groups of children.

\section{Clinical recommendation}

Although assessment of airway inflammation seems intuitively to be desirable, as yet there is no firm evidence that it is clinically useful.

\section{Research recommendation}

Research protocols should incorporate where feasible: 1 ) variable flow FeNO measurements; 2) induced sputum cell counts; 3) storage of induced sputum supernatant and cell pellets, and EBC samples in a Biobank; and 4) serum, DNA and urine.

\section{Bronchoscopy}

In many paediatric pulmonology centres, fiberoptic bronchoscopy with BAL, endobronchial biopsy and bronchial brushing are routinely performed in children with problematic asthma. In addition to the macroscopic inspection of the large airways and the diagnosis of any structural defects, this allows for determination of remodelling and inflammatory responses, in particular in the proximal airways [10,77]. More experience is required to determine the clinical role of these techniques.

\section{Clinical recommendation}

Although bronchoscopy is widely used in some centres, as yet there is no firm evidence that it is useful. It may be indicated if the diagnosis is in doubt, or to assess structural anomalies, remodelling and inflammation in difficult cases.

\section{Research recommendation}

Research protocols should incorporate bronchoscopy where feasible, and establish a Biobank for storage of endobronchial biopsy, BAL fluid and bronchial epithelial cells. 


\section{STEP 4: ASSESS STEROID RESPONSE}

Steroid response in childhood is not uniformly defined, and there is no consensus as to type of test, duration, dosage and administration form. In terms of how to conduct a steroid trial for the treatment of difficult asthma in children aged 5-15 yrs, a recent study evaluated the efficacy of a single dose (in children aged $<10$ yrs) or multiple doses (given approximately once every 4 weeks to children aged $>10$ yrs) of intramuscular triamcinolone acetonide [78]. The number and dose of triamcinolone was based on clinical judgement, and the total dose varied from $20 \mathrm{mg}$ to $480 \mathrm{mg}$. Intramuscular triamcinolone resulted in significant improvement of a range of severity markers, and this was sustained beyond the 1 month pharmacological activity of the preparation. Thus, intramuscular triamcinolone might be a useful "short-term" therapy in difficult asthma in children, and is indicative of the potential steroid effect.

Clinical improvement in symptoms is usually reflected by an asthma control test. Several tests are available, such as the Asthma control questionnaire [79] or Asthma Control Test (ACT) [80]. Inflammatory response may be assessed by distribution of cell types in sputum or by FeNO if the former is not available. However, cost-benefit, validity and possible superiority of one of these methods for assessing steroid response in children are not clear. The response criteria listed below are, therefore, provisional and for discussion.

Complete response can be considered: with an improved in ACT score of 20 or higher; bronchodilator use for symptoms less than three times a week (excluding during acute viral infection and its aftermath); normal pre-bronchodilator FEV1 using appropriate reference ranges (no short-acting bronchodilator within $4 \mathrm{~h}$ of the test); and normal cellularity of induced sputum/normal FeNO.

Partial response can be considered as failure to meet the criteria for full response, but a partial response in one or more criteria is present, defined as: an improvement in the ACT score of at least 5 points; bronchodilator use reduced by $>50 \%$; FEV1 increase by $>12 \%$ predicted; in induced sputum a $>50 \%$ reduction in eosinophil percentage; and $>50 \%$ fall in FeNO, with the same caveats as mentioned previously.

No response can be considered as no significant change in any of these parameters.

Overall, steroid responsiveness may be considered at two levels. At the clinical level patients will probably only consider they have responded to steroids if their symptoms have improved. Furthermore, some children may respond well to steroids and yet never regain normal lung function values. At the research level, to facilitate comparisons between centres, the assessment of multiple domains of steroid responsiveness is attractive.

\section{Clinical recommendation}

There is no agreed definition of steroid response; probably the definition most acceptable to patients is improvement of symptoms.

\section{Research recommendation}

The response to a steroid trial should be recorded in terms of symptoms, spirometry, inflammatory markers and bronchodilator response, with the ultimate aim of reaching an appropriate definition of steroid responsiveness.

\section{CURRENT KNOWLEDGE GAPS AND CONCLUSION}

It is clear from this article that many techniques are used in the assessment of children with problematic severe asthma, but few have been validated. This group of children is very heterogeneous and no single centre is likely to see enough patients to be able to conduct randomised trials or move the field forwards with pathophysiological studies. Thus, international collaboration is essential. We suggest that this should start with a detailed evaluation of these patients using standardised methods, which will allow for building a large cohort of carefully characterised patients. The next step is to move to more objective methods of phenotyping, such as cluster or principle component analysis, in order to define homogeneous groups of children. These groups can then be used: 1) to refine testing and see which of the many techniques we have described previously is clinically useful; 2) to carry out randomised controlled trials of specific therapies in focussed groups of patients; and 3) to carry out mechanistic studies, including gene association studies, to try to unravel the question as to what makes this child's asthma difficult to control, and why the child does not respond to the simple medications which are so effective in most children.

\section{SUPPORT STATEMENT}

This article was initiated and financially supported by the Global Allergy and Asthma European Network (GA ${ }^{2}$ LEN; EU contract number FOOD-CT-2004-506378).

\section{STATEMENT OF INTEREST}

Statements of interest for G. Hedlin, G. Wennergren, F.M. de Benedictis, J.C. de Jongste, E. Baraldi, G.L. Piacentini and K.H. Carlsen can be found at www.erj.ersjournals.com/site $/ \mathrm{misc} /$ statements.xhtml

\section{ACKNOWLEDGEMENTS}

The author's affiliations are as follows. K.C. Lødrup Carlsen and K.H. Carlsen: Dept of Paediatrics, Oslo University Hospital and the Faculty of Medicine, University of Oslo, Oslo, Norway. G. Hedlin and C. Pedroletti: Dept of Women's and Children's Health, Karolinska Institutet, Stockholm, Sweden. A. Bush: Dept of Respiratory Paediatrics, Royal Brompton Hospital, London, UK. G. Wennergren: Dept of Paediatrics, University of Gothenburg, Queen Silvia Children's Hospital, Gothenburg, Sweden. F.M. de Benedictis: Dept of Paediatrics, Salesi Children's Hospital, Ancona, Italy. J.C. De Jongste: Dept of Paediatrics, Erasmus University Medical Center-Sophia Children's Hospital, Rotterdam, The Netherlands. E. Baraldi and A. Barbato: Dept of Paediatrics, University of Padova, School of Medicine, Padova, Italy. K. Malmström: Dept of Allergy, Helsinki University Central Hospital, Helsinki, Finland. P. Pohunek: Charles University, 2nd Faculty of Medicine and University Hospital Motol, Prague, Czech Republic. S. Pedersen: University of Southern Denmark, Dept of Paediatrics, Kolding Hospital, Kolding, Denmark. G.L. Piacentini: Dept of Paediatrics, University of Verona, Verona, Italy. R.J.M. Middelveld: The Centre for Allergy Research, Institute of Environmental Medicine, Karolinska Institutet, Stockholm, Sweden. The following authors are members of the Global Allergy and Asthma European Network $\left(G^{2} L E N\right)$ : K.C. Lødrup Carlsen, G. Wennergren, C. Pedroletti, K. Malmström, R.J.M. Middelveld and K.H. Carlsen.

The PSACI group consists of the following members. E. Baraldi and A. Barbato: Dept of Paediatrics, University of Padova, School of Medicine, Padova, Italy; F.M. de Benedictis: Dept of Paediatrics, Salesi Children's Hospital, Ancona, Italy; A.L. Boner, D.G. Peroni and 
G.L. Piacentini: Dept of Paediatrics, University of Verona, Verona, Italy; A. Bush and N.M. Wilson: Dept of Respiratory Paediatrics, Royal Brompton Hospital, London, UK; K.H. Carlsen and K. C. Lødrup Carlsen: Dept of Paediatrics, Oslo University Hospital, and the Faculty of Medicine, University of Oslo, Oslo, Norway; J.C. De Jongste: Dept of Paediatrics, Erasmus University Medical Center-Sophia Children's Hospital, Rotterdam, The Netherlands; E. Eber: Respiratory and Allergic Disease Division, Dept of Paediatrics and Adolescence Medicine, Medical University of Graz, Graz, Austria; G. Hedlin and C. Pedroletti: Dept of Women's and Children's Health, Karolinska Institutet, Stockholm, Sweden; K. Malmström: Dept of Allergy, Helsinki University Central Hospital, Helsinki, Finland; E. Melén: Institute of Environmental Medicine, Karolinska Institutet, Stockholm, Sweden; R.J.M. Middelveld: The Centre for Allergy Research, Institute of Environmental Medicine, Karolinska Institutet, Stockholm, Sweden; N. Papadopoulos and P. Xepapadaki: Allergy Research Center, University of Athens, Athens, Greece; J. Paton: Division of Developmental Medicine, University of Glasgow, Royal Hospital for Sick Children, Glasgow, UK; S. Pedersen: University of Southern Denmark, Dept of Paediatrics, Kolding Hospital, Kolding, Denmark; P. Pohunek: Charles University, 2nd Faculty of Medicine and University Hospital Motol, Prague, Czech Republic; G. Roberts: University Child Health, University of Southampton School of Medicine, Southampton, UK; G. Wennergren: Dept of Paediatrics, University of Gothenburg, Queen Silvia Children's Hospital, Gothenburg, Sweden.

\section{REFERENCES}

1 Lang A, Carlsen KH, Haaland G, et al. Severe asthma in childhood: assessed in 10 year olds in a birth cohort study. Allergy 2008; 63: 1054-1060.

2 Konradsen JR, Nordlund B, Lidegran M, et al. Problematic severe asthma: a proposed approach to identifying children who are severely resistant to therapy. Pediatr Allergy Immunol 2010; [Epub ahead of print DOI: 10.1111/j.1399-3038.2010.01098.x].

3 Bracken M, Fleming L, Hall P, et al. The importance of nurse-led home visits in the assessment of children with problematic asthma. Arch Dis Child 2009; 94: 780-784.

4 Hedlin G, Bush A, Lødrup Carlsen K, et al. Problematic severe asthma in children: not one problem but many. A GA ${ }^{2}$ LEN initiative. Eur Respir J 2010; 36: 196-201.

5 Humbert M, Beasley R, Ayres J, et al. Benefits of omalizumab as add-on therapy in patients with severe persistent asthma who are inadequately controlled despite best available therapy (GINA 2002 step 4 treatment): INNOVATE. Allergy 2005; 60: 309-316.

6 Bateman ED, Cheung D, Lapa e Silva J, et al. Randomized comparison of ciclesonide 160 and $640 \mu \mathrm{g} /$ day in severe asthma. Pulm Pharmacol Ther 2008; 21: 489-498.

7 National Asthma Education and Prevention Program, Expert Panel Report 3 (EPR-3): Guidelines for the Diagnosis and Management of Asthma-Summary Report 2007. J Allergy Clin Immunol 2007; 120: Suppl. 5, S94-S138.

8 Bateman ED, Hurd SS, Barnes PJ, et al. Global strategy for asthma management and prevention: GINA executive summary. Eur Respir J 2008; 31: 143-178.

9 Taylor DR, Bateman ED, Boulet LP, et al. A new perspective on concepts of asthma severity and control. Eur Respir J 2008; 32: 545-554.

10 Jenkins HA, Cherniack R, Szefler SJ, et al. A comparison of the clinical characteristics of children and adults with severe asthma. Chest 2003; 124: 1318-1324.

11 Bacharier LB, Strunk RC, Mauger D, et al. Classifying asthma severity in children: mismatch between symptoms, medication use, and lung function. Am J Respir Crit Care Med 2004; 170: 426-432.
12 Lang A, Konradsen J, Carlsen $\mathrm{KH}$, et al. Identifying severe problematic asthma in the individual child: does lung function matter? Acta Paediatr Scand 2010; 99: 404-410.

13 O'Byrne PM, Pedersen S, Lamm CJ, et al. Severe exacerbations and decline in lung function in asthma. Am J Respir Crit Care Med 2009; 179: 19-24.

14 Fitzpatrick AM, Gaston BM, Erzurum SC, et al. Features of severe asthma in school-age children: atopy and increased exhaled nitric oxide. J Allergy Clin Immunol 2006; 118: 1218-1225.

15 Paull K, Covar R, Jain N, et al. Do NHLBI lung function criteria apply to children? A cross-sectional evaluation of childhood asthma at National Jewish Medical and Research Center, 1999-2002. Pediatr Pulmonol 2005; 39: 311-317.

16 Quanjer PH, Borsboom GJ, Kivastik J, et al. Cross-sectional and longitudinal spirometry in children and adolescents: interpretative strategies. Am J Respir Crit Care Med 2008; 178: 1262-1270.

17 Gold DR, Wypij D, Wang X, et al. Gender- and race-specific effects of asthma and wheeze on level and growth of lung function in children in six U.S. cities. Am J Respir Crit Care Med 1994; 149: 1198-1208.

18 Weiss ST, Van Natta ML, Zeiger RS. Relationship between increased airway responsiveness and asthma severity in the childhood asthma management program. Am J Respir Crit Care Med 2000; 162: 50-56.

19 Avital A, Godfrey S, Springer C. Exercise, methacholine, and adenosine $5^{\prime}$-monophosphate challenges in children with asthma: relation to severity of the disease. Pediatr Pulmonol 2000; 30: 207-214.

20 Lang AM MP, Sachs-Olsen C, Riiser A, et al. Asthma severity in childhood, untangling clinical phenotypes. Pediatr Allergy Immunol 2010; 21: 945-953.

21 Mussaffi H, Springer C, Godfrey S. Increased bronchial responsiveness to exercise and histamine after allergen challenge in children with asthma. J Allergy Clin Immunol 1986; 77: 48-52.

22 Cabral AL, Conceicao GM, Fonseca-Guedes CH, et al. Exerciseinduced bronchospasm in children: effects of asthma severity. Am J Respir Crit Care Med 1999; 159: 1819-1823.

23 Carlsen KH, Engh G, Mork M. Exercise-induced bronchoconstriction depends on exercise load. Respir Med 2000; 94: 750-755.

24 Carlsen KH, Engh G, Mork M, et al. Cold air inhalation and exercise-induced bronchoconstriction in relationship to metacholine bronchial responsiveness: different patterns in asthmatic children and children with other chronic lung diseases. Respir Med 1998; 92: 308-315.

25 Rosenthal RR. Simplified eucapnic voluntary hyperventilation challenge. J Allergy Clin Immunol 1984; 73: 676-679.

26 Brannan JD, Koskela H, Anderson SD, et al. Responsiveness to mannitol in asthmatic subjects with exercise- and hyperventilationinduced asthma. Am J Respir Crit Care Med 1998; 158: 1120-1126.

27 Anderson SD, Brannan JD. Methods for "indirect" challenge tests including exercise, eucapnic voluntary hyperpnea, and hypertonic aerosols. Clin Rev Allergy Immunol 2003; 24: 27-54.

28 Nuijsink M, Hop WC, Sterk PJ, et al. Long-term asthma treatment guided by airway hyperresponsiveness in children: a randomised controlled trial. Eur Respir J 2007; 30: 457-466.

29 Sont JK, Willems LN, Bel EH, et al. Clinical control and histopathologic outcome of asthma when using airway hyperresponsiveness as an additional guide to long-term treatment. The AMPUL Study Group. Am J Respir Crit Care Med 1999; 159: 1043-1051.

30 Lemanske RF Jr, Mauger DT, Sorkness CA, et al. Step-up therapy for children with uncontrolled asthma receiving inhaled corticosteroids. N Engl J Med 2010; 362: 975-985.

31 Reddel HK, Taylor DR, Bateman ED, et al. An official American Thoracic Society/European Respiratory Society statement: asthma control and exacerbations: standardizing endpoints for clinical 
asthma trials and clinical practice. Am J Respir Crit Care Med 2009; 180: 59-99.

32 Rasmussen F, Taylor DR, Flannery EM, et al. Risk factors for airway remodeling in asthma manifested by a low postbronchodilator FEV1/vital capacity ratio: a longitudinal population study from childhood to adulthood. Am J Respir Crit Care Med 2002; 165 1480-1488.

33 Wang J, Visness CM, Calatroni A, et al. Effect of environmental allergen sensitization on asthma morbidity in inner-city asthmatic children. Clin Exp Allergy 2009; 39: 1381-1389.

34 Gaffin JM, Phipatanakul W. The role of indoor allergens in the development of asthma. Curr Opin Allergy Clin Immunol 2009; 9: 128-135.

35 Denning DW, O'Driscoll BR, Hogaboam CM, et al. The link between fungi and severe asthma: a summary of the evidence. Eur Respir J 2006; 27: 615-626.

36 Bergstrom SE, Boman G, Eriksson L, et al. Asthma mortality among Swedish children and young adults, a 10-year study. Respir Med 2008; 102: 1335-1341.

37 Burbach GJ, Heinzerling LM, Edenharter G, et al. GA(2)LEN skin test study II: clinical relevance of inhalant allergen sensitizations in Europe. Allergy 2009; 64: 1507-1515.

38 Ando H, Moverare R, Kondo Y, et al. Utility of ovomucoid-specific IgE concentrations in predicting symptomatic egg allergy. J Allergy Clin Immunol 2008; 122: 583-588.

39 Gotzsche PC, Johansen HK. House dust mite control measures for asthma: systematic review. Allergy 2008; 63: 646-659.

40 de Vries MP, van den Bemt L, Aretz K, et al. House dust mite allergen avoidance and self-management in allergic patients with asthma: randomised controlled trial. Br J Gen Pract 2007; 57: 184-190.

41 Bush RK. Indoor allergens, environmental avoidance, and allergic respiratory disease. Allergy Asthma Proc 2008; 29: 575-579.

42 van den Bemt L, de Vries MP, Cloosterman S, et al. Influence of house dust mite impermeable covers on health-related quality of life of adult patients with asthma: results of a randomized clinical trial. J Asthma 2007; 44: 843-848.

43 McKinley L, Alcorn JF, Peterson A, et al. TH17 cells mediate steroid-resistant airway inflammation and airway hyperresponsiveness in mice. J Immunol 2008; 181: 4089-4097.

44 Adcock IM, Ford PA, Bhavsar P, et al. Steroid resistance in asthma: mechanisms and treatment options. Curr Allergy Asthma Rep 2008; 8: 171-178.

45 Murray CS, Poletti G, Kebadze T, et al. Study of modifiable risk factors for asthma exacerbations: virus infection and allergen exposure increase the risk of asthma hospital admissions in children. Thorax 2006; 61: 376-382.

46 Vicencio AG, Muzumdar H, Tsirilakis K, et al. Severe asthma with fungal sensitization in a child: response to itraconazole therapy. Pediatrics 2010; 125: e1255-e1258.

47 Annesi-Maesano I. Epidemiological evidence of the occurrence of rhinitis and sinusitis in asthmatics. Allergy 1999; 54: Suppl. 57, 7-13.

48 Braunstahl GJ. The unified immune system: respiratory tractnasobronchial interaction mechanisms in allergic airway disease. J Allergy Clin Immunol 2005; 115: 142-148.

49 Lipworth BJ, White PS. Allergic inflammation in the unified airway: start with the nose. Thorax 2000; 55: 878-881.

50 Tsao $\mathrm{CH}$, Chen LC, Yeh KW, et al. Concomitant chronic sinusitis treatment in children with mild asthma: the effect on bronchial hyperresponsiveness. Chest 2003; 123: 757-764.

51 Taramarcaz P, Gibson PG. Intranasal corticosteroids for asthma control in people with coexisting asthma and rhinitis. Cochrane Database Syst Rev 2003; 4: CD003570.

52 Triulzi F, Zirpoli S. Imaging techniques in the diagnosis and management of rhinosinusitis in children. Pediatr Allergy Immunol 2007; 18: Suppl. 18, 46-49.
53 Raherison C, Montaudon M, Stoll D, et al. How should nasal symptoms be investigated in asthma? A comparison of radiologic and endoscopic findings. Allergy 2004; 59: 821-826.

54 Bresciani M, Paradis L, Des Roches A, et al. Rhinosinusitis in severe asthma. J Allergy Clin Immunol 2001; 107: 73-80.

55 Campanella SG, Asher MI. Current controversies: sinus disease and the lower airways. Pediatr Pulmonol 2001; 31: 165-172.

56 ten Brinke A, Grootendorst DC, Schmidt JT, et al. Chronic sinusitis in severe asthma is related to sputum eosinophilia. J Allergy Clin Immunol 2002; 109: 621-626.

57 Annett RD. Assessment of health status and quality of life outcomes for children with asthma. J Allergy Clin Immunol 2001; 107: Suppl. 5, S473-S481.

58 Sawyer MG, Spurrier N, Whaites L, et al. The relationship between asthma severity, family functioning and the healthrelated quality of life of children with asthma. Qual Life Res 2000; 9: 1105-1115.

59 Moy ML, Israel E, Weiss ST, et al. Clinical predictors of healthrelated quality of life depend on asthma severity. Am J Respir Crit Care Med 2001; 163: 924-929.

60 Juniper EF. Health-related quality of life in asthma. Curr Opin Pulm Med 1999; 5: 105-110.

61 Juniper EF, Guyatt GH, Feeny DH, et al. Measuring quality of life in children with asthma. Qual Life Res 1996; 5: 35-46.

62 Marchac V, Emond S, Mamou-Mani T, et al. Thoracic CT in pediatric patients with difficult-to-treat asthma. AJR Am J Roentgenol 2002; 179: 1245-1252.

63 Saglani S, Papaioannou G, Khoo L, et al. Can HRCT be used as a marker of airway remodelling in children with difficult asthma? Respir Res 2006; 7: 46.

64 de Blic J, Tillie-Leblond I, Emond S, et al. High-resolution computed tomography scan and airway remodeling in children with severe asthma. J Allergy Clin Immunol 2005; 116 : 750-754.

65 Jentzsch NS, Camargos PA, Colosimo EA, et al. Monitoring adherence to beclomethasone in asthmatic children and adolescents through four different methods. Allergy 2009; 64: 1458-1462.

66 Lex C, Ferreira F, Zacharasiewicz A, et al. Airway eosinophilia in children with severe asthma: predictive values of noninvasive tests. Am J Respir Crit Care Med 2006; 174: 1286-1291.

67 Payne DN, Adcock IM, Wilson NM, et al. Relationship between exhaled nitric oxide and mucosal eosinophilic inflammation in children with difficult asthma, after treatment with oral prednisolone. Am J Respir Crit Care Med 2001; 164: 1376-1381.

68 van Veen $\mathrm{IH}$, Ten Brinke A, Sterk PJ, et al. Exhaled nitric oxide predicts lung function decline in difficult-to-treat asthma. Eur Respir J 2008; 32: 344-349.

69 Gibson PG, Norzila MZ, Fakes K, et al. Pattern of airway inflammation and its determinants in children with acute severe asthma. Pediatr Pulmonol 1999; 28: 261-270.

70 Djukanovic R, Sterk PJ, Fahy JV, et al. Standardised methodology of sputum induction and processing. Eur Respir J Suppl 2002; 20: Suppl. 37, 1s-2s.

71 Lex C, Payne DN, Zacharasiewicz A, et al. Sputum induction in children with difficult asthma: safety, feasibility, and inflammatory cell pattern. Pediatr Pulmonol 2005; 39: 318-324.

72 Wilson NM, Bridge P, Spanevello A, et al. Induced sputum in children: feasibility, repeatability, and relation of findings to asthma severity. Thorax 2000; 55: 768-774.

73 Li AM, Tsang TW, Chan DF, et al. Sputum induction in children with asthma: a tertiary-center experience. Pediatr Pulmonol 2006 41: 720-725.

74 Horvath I, Hunt J, Barnes PJ, et al. Exhaled breath condensate: methodological recommendations and unresolved questions. Eur Respir J 2005; 26: 523-548. 
75 Carraro S, Cogo PE, Isak I, et al. EIA and GC/MS analysis of 8-isoprostane in EBC of children with problematic asthma. Eur Respir J 2010; 35: 1364-1369.

76 Carraro S, Rezzi S, Reniero F, et al. Metabolomics applied to exhaled breath condensate in childhood asthma. Am J Respir Crit Care Med 2007; 175: 986-990.

77 Saglani S, Malmstrom K, Pelkonen AS, et al. Airway remodeling and inflammation in symptomatic infants with reversible airflow obstruction. Am J Respir Crit Care Med 2005; 171: 722-727.
78 Juniper EF, Gruffydd-Jones K, Ward S, et al. Asthma Control Questionnaire in children: validation, measurement properties, interpretation. Eur Respir J 2010; 36: 1410-1416.

79 Wallenstein GV, Carranza-Rosenzweig J, Kosinski M, et al. A psychometric comparison of three patient-based measures of asthma control. Curr Med Res Opin 2007; 23: 369-377.

80 Panickar JR, Kenia P, Silverman M, et al. Intramuscular triamcinolone for difficult asthma. Pediatr Pulmonol 2005; 39: $421-425$. 